\title{
THE VEHICLE ECOSYSTEM
}

\author{
Jonas Kuschel \\ IT University of Göteborg \\ Göteborg, Sweden
}

\begin{abstract}
Ubiquitous computing in the vehicle industry has primarily focused on sensor data serving different ubiquitous on-board services (e.g., crash detection, antilock brake systems, or air conditioning). These services mainly address vehicle drivers while driving. However, in view of the role of vehicles in today's society, it goes without saying that vehicles relate to more than just the driver or occupants; they are part of a larger ecosystem, including traffic participants, authorities, customers and the like. To serve the ecosystem with ubiquitous services based on vehicle sensor data, there is a need for an open information infrastructure that enables service development close to the customer. This paper presents results from a research project on designing such an infrastructure at a major European vehicle manufacturer. Our empirical data shows how the vehicle manufacturer's conceptualization of services disagrees with the needs of vehicle stakeholders in a more comprehensive vehicle ecosystem. In light of this, we discuss the effect on information infrastructure design and introduce the distinction between information infrastructure as product feature and service facilitator. In a more general way, we highlight the importance of information infrastructure to contextualize the vehicle as part of a larger ecosystem and thus support open innovation.
\end{abstract}

Keywords Information infrastructure, services, ecosystem, open innovation

\section{INTRODUCTION}

Vehicles are probably one of the most mature ubiquitous computing environments. An increasing number of sensors and microcomputers control, measure, and operate various vehicle components. The sensor data facilitates ubiquitous services, such as air bag inflation or injection control, which we take for granted when driving. However,

Please use the following format when citing this chapter:

Kuschel, J., 2008, in IFIP International Federation for Information Processing, Volume 287, Open IT-Based Innovation: Moving Towards Cooperative IT Transfer and Knowledge Diffusion, eds. León, G., Bernardos, A., Casar, J., Kautz, K., and DeGross, J. (Boston: Springer), pp. 309-322. 
most vehicle services are limited to the vehicle per se, even though there is a demand for making use of vehicle sensor data remotely. Remote vehicle diagnostics is one of the more prominent service directions in which the vehicle industry is heading, but has yet not succeeded in achieving. In this paper, our aim is to gain insights about the conceptualization and design of open information infrastructure to enable vehicle service innovations across the vehicle ecosystem.

The motivation to conduct research on remote vehicle services is constituted by the central role vehicles play in modern economies, since they carry assets, are part of widespanning workflows, affect the environment, or account for a company's assets. The role of a vehicle could thus be described as a node in a large interconnected ecosystem with various interfaces and interdependencies to various stakeholders and processes. These interdependencies would benefit from ubiquitous data describing the status of the vehicle, its load, or even its context to enhance existing processes or drive the innovation of novel services. However, there is as yet a lack of infrastructures and standards that support data exchange among the parts of the ecosystem (see Andersson 2006).

Our research thus aims to understand challenges in developing open information infrastructures that support service innovation and development among the ecosystem's stakeholders. In doing this, we have conducted a case study in collaboration with a major European vehicle manufacturer, where we participated in a research and development group working on infrastructure development for remote vehicle services. We spent a period of four months full-time work as project members to study a phenomenon through intervention. In doing this, we influenced the project work by introducing infrastructural thinking as described by Kuschel and Dahlbom (2007). The project had been initiated by the vehicle manufacturer since current remote vehicle services are provided by three different systems, each covering different brands or geographical markets. To achieve a homogenous solution, communication hardware on the vehicle is about to be consolidated, but the non-vehicle (off board) systems are still redundant. This makes the development of remote vehicle services costly, time extensive, and inflexible.

Information infrastructure theory outlines four major challenges in developing infrastructures: heterogeneity, evolution, control, and standardization (Nielsen 2006). Our aim here is to add to the understanding of heterogeneity, especially regarding organizations that change their business operations from products to services. Based on empirical observations, we show how the conceptualization of services affects the understanding and thus the design of information infrastructure. We argue that a product focus, such as services supporting products (Mathieu 2001), results in an understanding of information infrastructure that only mirrors vehicle features and functionalities. By applying a user perspective instead, vehicles turn out to be actors in a larger ecosystem where the information infrastructure acts as integration facilitator. We conclude that this constitutes the very condition for open innovation and thus heterogeneity.

The paper is organized as follows. In section 2, we outline our theoretical framework by presenting the theory of open information infrastructure. This is followed, in section 3 , by a presentation of the research setting and method applied. The empirical findings are reported in section 4, and then discussed in section 5. Finally, in section 6, we see how the conceptualization of service relates to information infrastructure development and open innovation of services. 


\section{OPEN INFORMATION INFRASTRUCTURE}

The advance of ubiquitous computing technology is about to change information technology services. As sensor and computing technology moves into the fabrics of everyday life, it is possible to gather personal customer information wherever the customer is located. This information may account for the basis of a service customization (e.g., changing vehicle services from being static and autonomous to ubiquitous and personal). As Fano and Gershman (2002) argue, ubiquitous services and business are about moving the location of business to the customer's location to provide services at the point of need rather than consuming services at the point of offer. This perspective complements Dourish's (2001) theory of embodied interaction: technologies participate in the world they represent. Information infrastructure is described as an important facilitator for such future nomadic and ubiquitous computing environments, where social and technical elements are combined (Lyytinen and Yoo 2002). Here we make use of the concept of open or universal information infrastructure, which Hanseth and Lyytinen (2004) describe as generally open to all possible users, even across different business sectors.

Nielsen (2006) outlines four analytical core concepts and challenges for building information infrastructures. These are heterogeneity, evolution, control, and standardization. Even though heterogeneity has been described by Nielsen as a major challenge in the literature, it also serves as the very condition for infrastructures to secure their growth. Due to the high level of heterogeneity, information infrastructures are described as evolving, influenced by their dependency path and the networks with which they are connected (Hanseth 2000). Nielsen describes this as interplay between evolution and construction. Ciborra et al. (2000), on the other hand, argue the development of information infrastructures to be out of control and drifting.

Information infrastructures require standardizations, socio-technical agreements about the properties of the infrastructure interface toward other infrastructures or systems (Hanseth and Monteiro 1997). This could be either the standardization of railway track widths to enable travel between two different railway networks or the standardization of TCP/IP to allow communication between various applications through, for example, the Internet. Since standardization is a mutual agreement between different representatives, negotiations may be tedious. Dahlbom (2000) describes infrastructures and standards as a relic of the material world, whereas information technology is immaterial and in essence a gateway technology making universal standardization less important. Hanseth et al. (1996) describe this phenomenon as the tension between standardization and flexibility in information infrastructure.

The role of information infrastructures and standards in the transportation industry has been described by Andersson (2007), who discusses the mobile-stationary divide as a challenge to integrate mobile vehicle systems and stationary management or transportation systems. Such integration will provide contextual data, such as driver tracking, which may imply social issues as a trade-off to efficiency and flexibility earnings. To address the technological challenges of the mobile-stationary divide in the transportation industry, a mobile-stationary interface standard has been implemented by a group ${ }^{1}$

${ }^{1}$ MSI Group (Mobile Stationary Interface Group). For further information, go to http://www.msigroup.se). 
representing various stakeholders. However, Andersson (2007) describes the implementation as a problematic negotiation due to vehicle producers' proprietary standpoints, underlying their ambition to keep contextual data for future services. Hence, the MSI standard exemplifies the vehicle industries' reluctance to openness such as in open information infrastructures.

Banavar et al. (2005) describe modern businesses as increasingly responsive to their environment or "context ecosystem." They argue that since the context ecosystem comprises various context data providers, there is a need for a middleware to handle contextual data across different stakeholders of the ecosystem. Kuschel and Dahlbom(2007) support a similar approach within the vehicle industry, outlining open information infrastructure as a key condition for mobile services.

Bruno Latour's (1996) insights from the development of the French autonomous train system, Aramis, may provide a good understanding of what we here refer to as open information. The goal of the Aramis project was to create a public transportation system where the subway's efficiency was supposed to be combined with the flexibility of automobiles. This was achieved by not physically linking parts of the train set, but interconnecting them virtually by a computer driven model controlling the wagons. In this way, a number of wagons were able to travel the same track until reaching a junction, where each wagon easily could choose a different track without physically decoupling them. Wagons were designed as small units with only six seats and all passengers were required to be seated. The idea was to design an efficient and flexible transportation system for the Paris region and similar projects were ongoing in other locations (for instance, Lyon). However, Aramis did not succeed even though the project lasted for 20 years and large amounts of money were spent. Latour analyses the failure of Aramis by pointing out the autonomy of technology in the project. An electric engine driving each wheel was considered as the most promising invention. However, the engine was only applicable to Aramis itself. Further, field trials on the applicability of Aramis showed that it was practically and economically not feasible to operate wagons with only six seated passengers, even though technical field trials showed very good results. This exemplifies how technology development in large projects faces a risk of running into developing autonomous technologies that, in the end, are not applicable to the proposed settings. Furthermore, the Aramis project and Latour's work provide insights on the network of subjects and objects (i.e., the nonexistence of complete autonomous objects as assumed by the Aramis project). In applying these thoughts to open information infrastructure, we here refer to openness as the condition for the network of objects and subjects to evolve.

\section{RESEARCH CONTEXT AND METHOD}

This paper is based on a case study at a major European vehicle manufacturer. The project was initiated by the vehicle manufacturer to investigate the design of a future information infrastructure for remote vehicle services, such as remote vehicle diagnosis. We joined the project as participating researchers. Lyytinen and Yoo (2002, p. 386) point to the local and personal characteristics of nomadic and ubiquitous computing, which requires an "examination of phenomena as it unfolds." They consider various 
anthropological methods to be promising in future IS research on nomadic and ubiquitous computing. Thus we combined ethnographic research (see Hughes et al. 1994; Schultze 2000) with participatory action research (Lau 1997), which provides us with observations through intervention.

In the first part of our work, we conducted an ethnographic field study at six different repair service workshops in five European countries. This study aimed to gather insights on the demand of remote vehicle services at dealerships, which are considered to play a major role in the retail and provisioning of future remote vehicle services. Furthermore, the study provided us with an understanding of existing systems. We spent one working day at each organization, observing day-to-day work practices, asking complementary questions and interviewing workshop managers, salesmen, chief diagnosticians, and service coordinators.

Our ethnographic work was followed up by a collaborative research project involving three employees from the vehicle manufacturer and one researcher. The researcher worked on a daily basis together with one of the employees and every month group meetings were held. However, discussions and ideas were exchanged frequently in shorter meetings or joint coffee breaks. All project members were situated in the same open office space. At the end of the project, a larger workshop, including product developers, was held. Our work has been documented by continuous annotations and joint internal presentations. However, the methodological focus was to intervene in the project work rather than to observe the project members' work. Therefore, our empirical work includes as well a retrospective analysis.

The objective of our research was to contribute to the project with knowledge on open information infrastructure since the concept of open information infrastructure is described as a condition to boost the development of remote vehicle services (Kuschel and Dahlbom 2007). There are currently three concurrent systems within the company that are operated by different brands or regional markets. The variety of systems is a result of acquisitions and autonomous decisions by some geographic market. However, there is ongoing work to consolidate different systems and the decision has already been made to share the same vehicle hardware across the three systems (see Figure 1, on-board vehicle platform). Nevertheless, off-board system implementations are not affected yet.

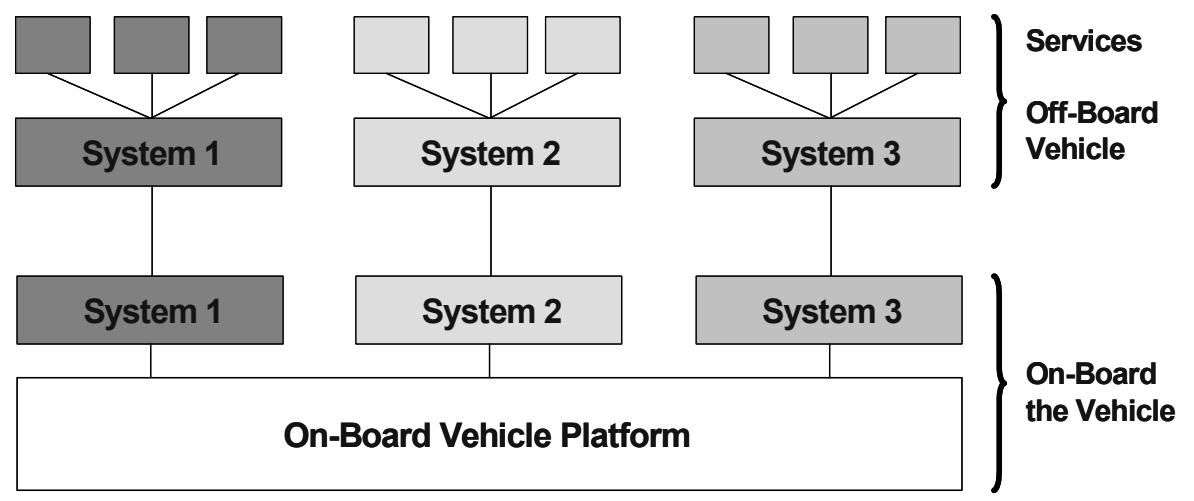

Figure 1. Overview of Current System and Service Structure 
The systems differ in their market penetration, technological level, and internal support. One system has gained market success quickly, the second is considered to be technically superior, and the third has support from higher management and long-term market experience. The current systems are so-called fleet management systems that facilitate communication, control, and scheduling of a truck fleet. They make use of vehicle information such as mileage, fuel consumption, average speed, stand-still time, gear shifts, drive time, and geographical position. Two of the systems also provide some vehicle diagnostic data as input to a repair process. All data is currently incorporated in end customer services, which makes it difficult to provide the data to other vehicle stakeholders. Thus, vehicle manufacturers face a situation of not being able to address the increasing demand for remote vehicle services, since changes to the current solutions are costly and complex. To address the bottleneck situation constituted by systems that are not designed for additional application areas, this infrastructure pre-study project was initiated by the vehicle manufacturer. We mainly focused on one of the three systems.

\section{FINDINGS}

In what follows we report our empirical results, which reflect the four-month project work in collaboration with a European vehicle manufacturer. The results are partly structured by the main research activities (i.e., the initial fieldwork, which is reported in the first two sections, and the collaborative research project reported in the remaining sections). Our work shows the need to embrace heterogeneity by identifying the current lack thereof. Furthermore, we describe possibilities for integrating vehicle information into existing processes, which may span the stakeholders of a larger vehicle ecosystem. Finally, we identify the current system complexity and the organizational resistance challenging such integration.

\subsection{Embracing Heterogeneity}

The current remote vehicle service system provided by the vehicle manufacturer is a web-based portal that collects different services such as messaging between driver and dispatcher, geographic tracking, usage reports, and service planning based on mileage information. The system requires additional hardware to be installed on the vehicle, but services are accessible through a generic web interface.

We did not include the actual use of the fleet management system in our study, but discussed the sales and user feedback experienced by sales and service personnel. There was a broad span of reactions to the current system. Some respondents did see a market potential in the current solution, whereas others did not even try to sell the system to their customers because they could not identify any sales arguments. However, what unites all of the interviewees included in this study is their concern that the system does not embrace change quickly enough. Customers demand additional services, but the current system cannot comply; however, competitive solutions manage to address market demands quickly. 
It seems to me that we are always a step behind. The system is technically good, despite the current problems with the new version. (Belgian sales manager)

The system is meant for transporters, but our customers are contractors and therefore it is difficult to compete against other systems. (British sales manager)

Another sales person outlined the need for local customizations or even specific services for some customers.

In the garbage collection business we have customers that invoice local authorities based on the actual mileage they have driven for collecting the garbage. Both parties are interested in receiving this data to feed their invoice and control systems. (Danish workshop manager)

Even though there is a demand for remote vehicle services, repair workshops cannot provide local implementations, since all services are managed on a global solution level. Pushing local demands to a global service is considered meaningless, resulting in successful third party providers that make use of their market knowledge and a faster speed to market process.

\subsection{Integration}

By observing day-to-day work at different repair workshops, we were able to study ordinary work processes to understand the current role and the future potential of remote vehicle services. We here present our empirical data, that shows the need to integrate remote vehicle services into existing processes, work procedures, and interaction patterns. In particular, we provide data on how remote vehicle services could support processes other than fleet management, which is the focus of the current systems.

I most often read out the fault codes before I delegate the job to a mechanic. I just print out the codes like this [shows a print out of error codes registered by the vehicle control system] and attach it at the back of the work order.

(Chief mechanic at a Belgian workshop)

This example shows how remote vehicle information (e.g., diagnostic error codes) constitute beneficial input to the repair work description. Currently the chief mechanic connects each truck to a diagnostic computer and prints the information. In other workshops, mechanics conduct this procedure themselves during each repair. However, by integrating the remote diagnostic information into the work planning system, workshop scheduling and service preparation would be enhanced without requiring additional activities such as described in the example. The following excerpt exemplifies another lack of process integration: 
We have to ask each customer about the current mileage when they arrive for service. This information we enter into a central system and then our financial service company uses the information to adjust service and leasing contracts. If the mileage differs from previous estimations, this sometimes causes trouble. Customers call us and are angry about being invoiced without expecting it. We then have to explain that they have exceeded their forecasted mileage. (Belgian workshop owner and manager)

In this case, continuous updates of mileage information would enhance the invoice process and save unwanted surprises to the customer. The financial service company would in turn benefit through adjusted cash flows. Furthermore, this example shows how small portions of remote vehicle information could improve larger existing processes and services. For instance, the same mileage information can also be used as input to the maintenance planning system that schedules service intervals.

With the new digital tachograph, drivers have to use a USB memory stick to collect the data for reporting. This is fairly complicated and should be much easier with new technology. (Swedish service manager)

This example shows how future remote vehicle services span a broader spectrum than remote vehicle diagnostics. Tachograph information describes the driver's working hours and is used by authorities, as well as for calculating the driver's salary, fleet planning, and such activities. In summary, these examples show how remote vehicle services could enhance existing services and processes. However, the empirical data also reveals the need to integrate remote vehicle services into day-to-day work practices and interaction patterns (i.e., to integrate into existing systems and work procedures), rather than providing additional ones. The following excerpts exemplify this problem:

The haulage company next door has provided us with their login credentials to the web portal. We then can login and check where the trucks are located and see if the truck will manage to arrive on time for service. We do this only for one customer, it's our boss' brother who owns the company, you know. It would be impossible to keep track of all passwords for our customers. (Belgian service coordinator)

We use [the system] on a daily basis and install it in all new units. However, it would be nice if we could use the information elsewhere. Now our customers call us and ask where the milk is. We then have to go into the system and check the vehicle's position. I mean that's a good service to our customers, but right now its tricky for us to arrange. (Fleet manager, British dairy company)

These examples show the importance of appropriate interaction possibilities as an essential part of remote vehicle services. The technical availability of vehicle information, per se, is not good enough and therefore information access has to be adequate to different work procedures. 


\subsection{Ecosystem}

The collaborative research project on infrastructure development started with a disagreement on what the focus of our work should be. From an industry perspective, there was a demand for a gap analysis between the three concurrent systems to contribute to the design of a new infrastructure.

It has to be said that I had a different understanding of the project the first day. My view was very pragmatic; I mean, let's make a gap analysis between the existing systems as input to the new infrastructure. In the aftermath, I am very happy that we chose another approach where we focused on understanding the concept of infrastructure first. (Project sponsor responding to an evaluation committee)

This retrospective comment on the project by the project sponsor confirms the importance of conceptualizing the role of information infrastructure. As the following excerpt reveals, there was a lack of understanding of what distinguishes systems from infrastructures:

PM1: $\quad$ Yes this should be included in the future portal, I agree.

PM2: I think we should be aware to distinguish between portal and infrastructure.

PM1: Ok, call it infrastructure instead I thought it's the same.

PM2: No, the idea is to facilitate for example the current portal by an underlying infrastructure. It is the infrastructure we currently lack.

We started off by establishing a joint understanding on two central concepts: service and infrastructure. As follows, we outline the discussion and negotiation on what constitutes information infrastructure and services in this specific context. By studying and analyzing previous documentation related to remote vehicle services, we found that the vehicle most often is outlined as centric and autonomous, neglecting the real world contextual setting. However, considering the role of modern vehicles in today's society, it is obvious that vehicles are part of a larger ecosystem including various stakeholders. We introduced this perspective as a foundation for conceptualizing the information infrastructure and the notion of service. By using this perspective, project members started to understand the information infrastructure as serving the ecosystem by offering integration services for the vehicle. Thus the notion of service changed from end customer services to infrastructural services, which in turn facilitate services making use of remote vehicle information in various settings. By this, we switched focus from the product as autonomous entity to the product as actor in a larger ecosystem.

\subsection{Complexity}

As part of our joint project work, we conducted a workshop with product development personnel to inform our design and to disseminate our results. The main problem 
pointed to by the workshop participants is the current lack of services and foremost difficulties in adding new services to the existing system (i.e., the web portal).

We currently cannot leverage new services that the market is asking for.

The lack of velocity in bringing new services to the market might be explained by the development cost related to the current system. A project manager stated resignedly,

There is nothing to get under... $€^{2}$ to make changes to the current system.

Such high development costs to implement new services indicates that the system is not designed to embrace change in any way. The system was initially designed for a defined purpose: an end user application. Furthermore, the defined purpose was reflected throughout the system and thus new requirements affect all parts of the system. This is a known problem, as the following excerpt and the previous one show.

The information has been designed for an end product, which makes it difficult to design new services with different requirements.

Workshop participants agreed upon the need to change the current situation. However, organizational issues rather than the system as such were pointed to as the cause of difficult situation. The following excerpts outline organizational structures as hampering the development of new services:

There are far too many stakeholders involved, which makes interfaces and roles unclear. The brands should focus more on which services to provide and less on technical solutions.

A lot of internal issues make it complex to create services.

We here witness both organizational and technical complexity. From an organizational perspective, it remains unclear what part of the organization is entitled to develop services. Technically, the current infrastructural systems are not flexible enough to embrace a change in service demand.

\subsection{Resistance}

Despite the problems pointed out, the current system and its service offerings were defended by some workshop participants. The complexity of selling services for an organization that is used to sell products is put forward as argument.

We do have the services but nobody is selling them.

${ }^{2}$ Due to a nondisclosure agreement, we cannot detail the figure. 


\section{It's different to sell services than trucks.}

One workshop participant extends the problem by pointing to the design of the current service offerings to be more like products than services.

We package too many services into one service package. We sell products like the current system rather than services such as navigation. It is difficult to make customizations.

The second objective of the workshop was to introduce the concept of open or general information infrastructure (Hanseth and Lyytinen 2004), that is, to enable a general audience to develop remote vehicle services based on a shared information infrastructure. The open information infrastructure concept presented incorporates both vehicle hardware and external software implementations. The infrastructure embodies vehicle communication as a core service upon which various infrastructural service layers can be implemented to offer appropriate interfaces to different stakeholder services. In this way, the infrastructure is supposed to better support the current bottleneck of service development and thus move the focus onto user-oriented services rather than current product features. However, when presenting the concept of information infrastructure as opposed to a system, the workshop participants did not fully agree. Since infrastructuralization implies increased openness, voices were being raised about the importance of ssafety.

You should be aware that these are objects of up to 60 tons that could kill people. We of course have a responsibility in this case.

Not only safety issues were put forward as arguments against an open information infrastructure, the majority of workshop participants adopted a defensive attitude in preference to the current system. This defensive attitude contradicts their initial criticism of the current system. Thus, the extent to which resistance to an open information infrastructure refers to fundamental arguments rather than uncertainty about openness is questionable.

\section{DISCUSSION}

Based on our empirical data, we identify different aspects that currently challenge information infrastructure and remote vehicle service development at a European vehicle manufacturer. These are embracing heterogeneity, integration as core service, understanding the vehicle as part of an ecosystem, and resistance to openness, which manifests in technical and organizational complexity. We here discuss how they relate to each other and constitute a general challenge to information infrastructure development.

The current approach to remote vehicle services reveals some fundamental similarities to the development of the French train system Aramis (Latour 1996). Both projects are based on an understanding of autonomous technology that lacks contextual integration, we argue. This is also a general problem of ubiquitous computing, as Dourish (2001) highlights in his thoughts on embodied interaction. Ubiquitous com- 
puting tends to primarily focus on the physical embodiment of technology — on minimization of computing power and extending sensor capacity - rather than embodying the use of technology in everyday life. In this paper, we highlight the role of information infrastructure to facilitate the embodiment of ubiquitous computing technology within its ecosystem.

Current remote vehicle services are designed as product features extending some selected vehicle properties. However, by studying service repair work as a future application area, we reveal a demand to embrace heterogeneity, constituted by a demand for local customizations. Furthermore, we show that these services have to be integrated into day-to-day work and processes to add user value. Thus, remote vehicle services are evolving and span heterogeneous technologies and organizations. Such socio-technical challenges in ubiquitous computing environments are best addressed by information infrastructures (Lyytinen and Yoo 2002). Even though we agree on the role of information infrastructure to leverage remote vehicle services, we here aim to stress the challenge of conceptualizing the underlying understanding of service and information infrastructure. In doing so, we distinguish between services as product features or representations and services that evolve by means of the heterogeneous network of which they are part. The latter extends the understanding of information infrastructures, from interfacing product features to instead enabling integration with the ecosystem.

However, our project reveals a resistance to such open innovation across the vehicle ecosystem. As we show, the resistance is manifested in both technical and organizational complexity. The development of new services is restricted by high development cost due to inflexibility in the current infrastructure design. The organizational complexity can be described by undefined roles and a lack of separating service development from information infrastructure development. The fleet management system in focus was developed and operated by a former spin off company, funded by different industrial investors. The company was acquired by the vehicle manufacturer to act as wholly owned but independent subsidiary. As a result of the company's independence and their strategy to also provide services to other vehicle manufacturers, they offer packaged end-customer services. Customizations are very limited and the service packages are considered of-theshelf services. There has been a protracted discussion whether the subsidiary company should be incorporated into the vehicle manufacturer's business unit for global IT operations. This discussion culminated during our project work and resulted in finally integrating the company into the business unit for IT operations. The strongest argument for the incorporation was to add local presence through the business unit's global operations, which is considered necessary to develop new services. This strategic decision supports the argument of separating service development from the core information infrastructure.

Remote vehicle services are traditionally understood as separate service offerings complementary to the vehicle. GM's OnStar and Daimler Chrysler's FleetBoard are other examples of vehicle manufacturers organizing their remote vehicle service offerings in subsidiaries. However, our field work reveals a demand for remote vehicle services as support to existing processes and work practices, which the current service offerings do not address. Thus, the incorporation of the subsidiary is a first step to better reach out within the organization and to understand how remote vehicle services span the organization as opposed to the current understanding of services as autonomous product features. Nevertheless, the demand for an openness across the ecosystem's various stake- 
holders remains in order to foster open innovation of services, which in turn provides the economic foundation for an information infrastructure in the vehicle industry (Kuschel and Dahlbom 2007).

\section{CONCLUSION}

Even though remote vehicle services such as remote vehicle diagnostics are considered to account for a major part of vehicle manufacturers' future revenues, manufacturers are still struggling to develop appropriate services. In this paper, we report on the results of developing an information infrastructure at a European vehicle manufacturer to facilitate service development. Our study shows a disagreement between customers' demand for integrating vehicle information into the boundary spanning ecosystem of vehicle operations and the manufacturers' understanding of information infrastructure as an extension of product features. We thus contribute to information infrastructure theory by showing how the conceptualization of service affects the understanding and design of information infrastructure. We distinguish between information infrastructures exposing products as autonomous objects and infrastructures embodying the product within its ecosystem by strengthening the interplay between, as Latour (1996) puts it, subject and object. Finally, we argue that understanding this interplay constitutes the very condition for open innovation in the vehicle industry.

\section{References}

Andersson, M. 2006. "Ubiqutious Transport Systems: Negotiating Context Through a Mobilestationary Interface," in Proceedings of the $14^{\text {th }}$ European Conference on Information Systems, J. Ljunberg and M. Andersson (eds.), Gothenburg, Sweden, pp. 2194-2205.

Andersson, M. 2007. Heterogeneous IT Innovation-Developing Industrial Architectural Knowledge, unpublished Ph.D. thesis, Department of Applied IT, University of Gothenburg, Sweden.

Banavar, G., Black, J., Cáceres, R., Ebling, M., Stern, E., and Kannry, J. 2005. "Deriving LongTerm Value from Context-Aware Computing," Information Systems Management (22:4), pp. $32-42$.

Ciborra, C., Braa, K., Cordella, A., Dahlbom, B., Failla, A., Hanseth, O., Hepsø, V., Ljungberg, J., Monteiro, E., and Simon, K. A. (eds.). 2000. From Control to Drift: The Dynamics of Corporate Information Infrastructures, Oxford, England: Oxford University Press.

Dahlbom, B. 2000. "Postface: From Infrastructure to Networking," in From Control to Drift: The Dynamics of Corporate Information Infrastructures, C. Ciborra, K. Braa, A. Cordella, B. Dahlbom, A. Failla, O. Hanseth, V. Hepsø, J. Ljungberg, E. Monteiro, and K. A. Simon (eds.), Oxford, England: Oxford University Press, pp. 212-226.

Dourish, P. 2001. Where the Action Is: The Foundations of Embodied Interaction, Cambridge, MA: MIT Press.

Fano, A., and Gershman, A. 2002. "The Future of Business Services in the Age of Ubiquitous Computing," Communications of the ACM (45:12), pp. 83-87.

Hanseth, O. 2000. "The Economics of Standards," in From Control to Drift: The Dynamics of Corporate Information Infrastructures, C. Ciborra, K. Braa, A. Cordella, B. Dahlbom, A. Failla, O. Hanseth, V. Hepsø, J. Ljungberg, E. Monteiro, and K. A. Simon (eds.), Oxford, England: Oxford University Press, pp. 56-70. 
Hanseth, O., and Lyytinen, K. 2004. "Theorizing about the Design of Information Infrastructures: Design Kernel Theories and Principles, Sprouts: Working Papers on Information, Environments Systems and Organizations (4:4) Article 12 (http://sprouts.case.edu/040412.cfm).

Hanseth, O., and Monteiro, E. 1997. "Inscribing Behavior in Information Infrastructure Standards," Accounting, Management and Information Technology (7:4), pp. 183-211.

Hanseth, O., Monteiro, E., and Hatling, M. 1996. "Developing Information Infrastructure: The Tension between Standardization and Flexibility," Science, Technology \& Human Values (21:4), pp. 407-426.

Hughes, J., King, V., Rodden, T., and Andersen, H. 1994. "Moving Out from the Control Room: Ethnography in System Design," in Proceedings of the 1994 ACM Conference on Computer Supported Cooperative Work, Chapel Hill, NC, pp. 429-439.

Kuschel, J., and Dahlbom, B. 2007. "Mobile Services for Vehicles," in Proceedings of the $15^{\text {th }}$ European Conference on Information Systems, H. Österle, J. Schelp, and R. Winter (eds.), University of St. Gallen, St. Gallen, Switzerland, pp. 1863-1874.

Latour, B. 1996. Aramis or the Love of Technology, Cambridge, MA: Harvard University Press.

Lau, F. 1997. "A Review on the Use of Action Research in Information Systems Studies," in Information Systems and Qualitative Research, A. S. Lee, J. Liebenau, and J. I. DeGross (eds.), London: Chapman \& Hall, pp. 31-68.

Lyytinen, K., and Yoo, Y. 2002. "Research Commentary: The Next Wave of Nomadic Computing," Information Systems Research, (13:4), pp. 377-388.

Mathieu, V. 2001. "Product Services: From a Service Supporting the Product to a Service Supporting the Client," Journal of Business \& Industrial Marketing (16:1), pp. 39-61.

Nielsen, P. 2006. A Conceptual Framework of Information Infrastructure Building: A Case Study of the Development of a Content Service Platform for Mobile Phones in Norway, unpublished Ph.D. thesis, Department of Informatics, University of Oslo, Norway.

Schultze, U. 2000. “A Confessional Account of an Ethnography about Knowledge Work," MIS Quarterly (24:1), pp. 3-41.

\section{About the Author}

Jonas Kuschel is a Ph.D. student at IT University of Göteborg, Sweden. His research deals with developing future services in the vehicle industry, with a particular focus on the interdependencies between user-oriented services and information infrastructures. He can be reached at jonas.kuschel@ituniv.se. 